OPEN ACCESS

Edited by:

Dennis John Cordato,

University of New South

Wales, Australia

Reviewed by:

Tobias Djamsched Faizy,

University Medical Center

Hamburg-Eppendorf, Germany

Norbert Nighoghossian,

Université Claude Bernard

Lyon 1, France

*Correspondence:

Gilles Naeije

Gilles.Naeije@erasme.ulb.ac.be

†These authors have contributed equally to this work

Specialty section:

This article was submitted to Stroke,

a section of the journal

Frontiers in Neurology

Received: 17 December 2021

Accepted: 28 January 2022

Published: 21 February 2022

Citation:

Ligot N, Elands S, Damien C, Jodaitis L, Sadeghi Meibodi $N$ Mine B, Bonnet T, Guenego A, Lubicz B and Naeije G (2022) Stroke Core Volume Weighs More Than Recanalization Time for Predicting Outcome in Large Vessel Occlusion

Recanalized Within $6 \mathrm{~h}$ of Symptoms Onset. Front. Neurol. 13:838192. doi: 10.3389/fneur.2022.838192

\section{Stroke Core Volume Weighs More Than Recanalization Time for Predicting Outcome in Large Vessel Occlusion Recanalized Within $6 \mathrm{~h}$ of Symptoms Onset}

\author{
Noemie Ligot ${ }^{1 \dagger}$, Sophie Elands ${ }^{1 \dagger}$, Charlotte Damien ${ }^{1}$, Lise Jodaitis ${ }^{1}$, \\ Niloufar Sadeghi Meibodi ${ }^{2}$, Benjamin Mine ${ }^{3}$, Thomas Bonnet ${ }^{3}$, Adrien Guenego ${ }^{3}$, \\ Boris Lubicz ${ }^{3}$ and Gilles Naeije ${ }^{1 *}$
}

\begin{abstract}
${ }^{1}$ Department of Neurology, CUB Hôpital Erasme, Université Libre de Bruxelles (ULB), Brussels, Belgium, ${ }^{2}$ Department of Radiology, CUB Hôpital Erasme, Université Libre de Bruxelles (ULB), Brussels, Belgium, ${ }^{3}$ Department of Interventional Neuroradiology, CUB Hôpital Erasme, Université Libre de Bruxelles (ULB), Brussels, Belgium
\end{abstract}

Introduction: Current guidelines suggest that perfusion imaging should only be performed $>6 \mathrm{~h}$ after symptom onset. Pathophysiologically, brain perfusion should matter whatever the elapsed time. We aimed to compare relative contribution of recanalization time and stroke core volume in predicting functional outcome in patients treated by endovascular thrombectomy within 6-h of stroke-onset.

Methods: Consecutive patients presenting between January 2015 and June 2021 with (i) an acute ischaemic stroke due to an anterior proximal occlusion, (ii) a successful thrombectomy $(\mathrm{TICl}>2 \mathrm{a}$ ) within 6-h of symptom-onset and (iii) CT perfusion imaging were included. Core stroke volume was automatically computed using RAPID software. Two linear regression models were built that included in the null hypothesis the pre-treatment NIHSS score and the hypoperfusion volume (Tmax $>6 \mathrm{~s}$ ) as confounding variables and $24 \mathrm{~h}$ post-recanalization NIHSS and 90 days $\mathrm{mRS}$ as outcome variables. Time to recanalization was used as covariate in one model and stroke core volume as covariate in the other.

Results: From a total of 377 thrombectomies, 94 matched selection criteria. The Model null hypothesis explained $37 \%$ of the variability for $24 \mathrm{~h}$ post-recanalization NIHSS and $42 \%$ of the variability for 90 days MRS. The core volume as covariate increased outcome variability prediction to 57 and $56 \%$, respectively. Time to recanalization as covariate marginally increased outcome variability prediction from 37 and $34 \%$ to 40 and $42.6 \%$, respectively.

Conclusion: Core stroke volume better explains outcome variability in comparison to the time to recanalization in anterior large vessel occlusion stroke with successful thrombectomy done within 6 h of symptoms onset. Still, a large part of outcome variability prediction fails to be explained by the usual predictors.

\footnotetext{
Keywords: large vessel occlusion, ischemic core, perfusion CT, within $6 \mathrm{~h}$ of onset, outcome
} 


\section{INTRODUCTION}

The anterior circulation of the human brain is provided by the anterior cerebral arteries (ACA) and middle cerebral arteries (MCA) that emerge from the internal carotid arteries (ICA). It is responsible for the irrigation of 422 out of the $541 \mathrm{~cm}^{3}$ of each hemisphere, including most of the motor and eloquent cortices (1). This explains why anterior circulation large vessel occlusions (LVO) account for over sixty percent of the morbidity and mortality related to stroke (2). Anastomoses between left and right anterior circulations, between posterior and anterior circulations through the Circle of Willis, as well as between leptomeningeal collaterals, may maintain a temporary blood supply to the brain territories affected by LVO. The effectiveness of those anastomoses delimitates both the ischemic core, defined as the critically hypoperfused tissue with low cerebral blood flow $(\mathrm{CBF})$ that will die regardless of subsequent reperfusion status, and the ischemic penumbra, defined as the "tissue at risk" that is potentially salvageable and has the capacity to recover if reperfusion is achieved (3).

In LVO, if recanalization therapy is feasible within $6 \mathrm{~h}$ of symptoms onset, there is a class I recommendation against performing brain perfusion imaging to select patients that may or may not benefit from thrombectomy. As the dictum goes "time is brain", and so a direct transfer to the angiography suite is favored over any delay needed for perfusion imaging acquisitions (4). On the other hand, if a patient with LVO presents between 6 and $24 \mathrm{~h}$ after symptom onset, recanalization is warranted only when perfusion parameters are deemed favorable $(5,6)$. However, given the underlying pathophysiology, perfusion analysis should give the same information whether imaging is done within $6 \mathrm{~h}$ of symptom onset or thereafter. Furthermore, amounting evidence shows that collateral status analysis supersedes the Time to Reperfusion (TTR) in predicting outcome from recanalization therapy $(7,8)$. Similarly, the HERMES collaboration that pooled patient-level data from all randomized controlled trials that compared endovascular thrombectomy with standard medical therapy in patients with an anterior circulation ischaemic stroke demonstrated that TTR mattered mostly for low stroke ischemic core volumes (9). Yet, actual recommendations argue against computed tomography perfusion (CTP) imaging in early onset LVO on the basis of: (1) the delay incurred in further imaging acquisitions, (2) the risk of potential overestimation of the core volume in early LVO (Ghost effect) (10) reported in as many as $50 \%$ of cases $(10,11),(3)$ the technical issues that make CTP unreliable in as many as $13 \%$ of cases (12). Still, the increasing number of patients treated by mechanical thrombectomy for LVO and the associated costs of the procedure plead an accurate selection of patients who will most benefit from the procedure within $6 \mathrm{~h}$ of symptom onset. Conceptually, despite its potential limitations, perfusion imaging still stands as a major contributor to recanalization therapy decision.

The aim of this study is to assess the relative importance of TTR and core volume estimated by the RAPID software in the outcome prediction of patients with a LVO occlusion presenting within $6 \mathrm{~h}$ of symptom onset with successful recanalization therapy. To do so, a regression analysis was done on a large monocentric cohort of patients to weigh the yield of perfusion analysis and TTR in early onset LVO.

\section{METHODS}

\section{Population}

The studied population is derived from the stroke registry of Erasmus Hospital in Brussels (Belgium) where all case of acute stroke since January 2015 are recorded and our analysis included patients admitted between January 2015 and June $2021(13,14)$. Inclusion criteria were patients presenting with (i) age over 18 years-old, (ii) acute anterior LVO, defined as an occlusion of the ICA (T-type), MCA (M1 or M2 segments) and ACA (A1 or A2 segments) (iii) successful recanalization defined as a reperfusion score of Thrombolysis in Cerebral Infarction (TICI) $>2 \mathrm{a}$, within $6 \mathrm{~h}$ of symptoms onset and (iv) perfusion CT imaging done within $6 \mathrm{~h}$ of symptom-onset with reliable analysis by Rapid software.

\section{Imaging}

Pre-interventional imaging included non-contrast CT, CT angiography and CT perfusion (CTP). Ischemic core was defined as brain volume with $\mathrm{CBF}$ under $30 \%$ of the $\mathrm{CBF}$ of the homologous zone in the contralateral hemisphere. Ischemic penumbra was defined as brain volumes where the $\mathrm{T}_{\max }$ of contrast product arrival exceeded $6 \mathrm{~s}$. Those volume were automatically computed with the Rapid software (15) on which the cut-offs were based on (6).

\section{Outcomes}

The primary outcome measure was functional outcome, using (1) the National Institutes of Health Stroke Scale (NIHSS) score at $24 \mathrm{~h}$ post-thrombectomy, and (2) a good clinical outcome at 90 days defined as a Modified Rankin Scale (mRS) score $\leq 3$.

\section{Statistical Analysis}

\section{Variable Definition and Regression Models}

Variable of interest were selected based on previous stroke outcome predictive models: Age in years (16), NIHSS at admission $(17,18)$, ischemic core $(9)$ and time to recanalization (TTR) (19) were chosen as covariates in a linear regression model to predict NIHSS $24 \mathrm{~h}$ post-recanalization. The aforementioned variables were chosen as covariates in a logistic regression model to predict a favorable stroke outcome at 90 days. The models' ability to predict favorable stroke outcomes were assessed by calculating the area under receiver operating characteristic curves (AUC) of sensitivity vs. (1-specificity). AUC is used to measure how well a model correctly classifies patients into two groups of favorable outcome or not. An AUC of 0.5 corresponds to a prediction that is no better than chance where $50 \%$ of patients would be assigned to each group, a higher AUC means better classification, and an AUC of one corresponds to perfect classification.

To assess the relative weight of ischemic core volume and TTR, admission NIHSS and age-both unmodifiable intrinsic patients stroke characteristics-were included in the null model as nuisance parameters. 
TABLE 1 | Clinical characteristics.

\begin{tabular}{|c|c|}
\hline Age (mean $\pm S D$, years) & $71 \pm 12$ \\
\hline $\operatorname{tPA}(n, \%)$ & $62(69)$ \\
\hline \multicolumn{2}{|l|}{ Occlusion location: } \\
\hline T-ICA $(n, \%)$ & $23(29)$ \\
\hline $\mathrm{M} 1(n, \%)$ & $54(64)$ \\
\hline $\mathrm{M} 2(n, \%)$ & $24(28)$ \\
\hline \multicolumn{2}{|l|}{ RAPID data analysis (mean $\pm \mathrm{SD}$ ) } \\
\hline $\mathrm{CBF}>30 \%$ vol & $26 \pm 36 \mathrm{ml}$ \\
\hline $\operatorname{Tmax}>6 \mathrm{~s}$ & $100 \pm 64 \mathrm{ml}$ \\
\hline Mismatch ratio & $13.4 \pm 14.2$ \\
\hline Mismatch volume & $74 \pm 50 \mathrm{ml}$ \\
\hline \multicolumn{2}{|l|}{ NIHSS Score (mean \pm SD) } \\
\hline Before therapy & $15 \pm 7$ \\
\hline $24 \mathrm{~h}$ after therapy & $9 \pm 8$ \\
\hline Difference & $-5 \pm 8$ \\
\hline Recanalisation time from onset & $217 \pm 99$ \\
\hline \multicolumn{2}{|l|}{ mRS score 90 days $(n=62)$} \\
\hline $0(n, \%)$ & $8(13)$ \\
\hline $1(n, \%)$ & $14(23)$ \\
\hline $2(n, \%)$ & $9(15)$ \\
\hline $3(n, \%)$ & $10(16)$ \\
\hline $4(n, \%)$ & $4(6)$ \\
\hline $5(n, \%)$ & $1(2)$ \\
\hline $6(n, \%)$ & $14(23)$ \\
\hline
\end{tabular}

SD, Standard Deviation; tPA, tissue Plasminogen Activator; ICA, Internal Carotid Artery; M1, M1 division of the Middle Cerebral Artery; M2, M2 division of the Middle Cerebral Artery; CBF, Cerebral Blood Flow; NIHSS, National Institutes of Health Stroke Scale; $m R S$, modified Rankin Scale.

\section{Correlations}

Pearson rank correlations were used for correlation between explanatory and outcome variables. Corrected $p$-values for multiple comparisons by Bonferroni was set at 0.017 .

\section{Ethics}

The study was reviewed and approved by the Ethics Committee of Erasmus Hospital, Brussels, Belgium. Written informed consent for participation was not required for this study in accordance with the national legislation and the institutional requirement.

\section{Data Availability}

Data can be shared upon reasonable request.

\section{RESULTS}

\section{Population}

We identified 102 successful LVO recanalizations occurring in patients who underwent thrombectomy within $6 \mathrm{~h}$ of symptom onset among the 377 thrombectomies realized in the period considered (Table 1). Reliable CTP analysis by the Rapid software was available for 94 of these patients who thus constituted the study cohort. Mean age was $71 \pm 12$ years. Mean admission
NIHSS was $15 \pm 7$. The rest of the clinical characteristics are summarized in Table 1.

\section{Correlation Analysis}

There was a significant correlation between ischemic core volume $(\mathrm{CBF}<30 \%)$ and NIHSS at $24 \mathrm{~h}$ post treatment $(r=0.62, p<$ $0.001)$ and between TTR and NIHSS at 24 h post treatment $(r=$ $0.25, p=0.017)$, but not between patients' age and NIHSS at $24 \mathrm{~h}$ post treatment $(r=0.19, p=0.076)$ (Figure 1).

\section{Linear Regression Model for NIHSS $24 \mathrm{~h}$ Post Treatment Prediction}

Table 2, illustrates the results of the linear regression model. This multiple linear regression model was statistically significant to predict NIHSS $24 \mathrm{~h}$ post treatment $\left(R^{2}=0.57, F_{(4,82)}=27.2\right.$, $p<0.001)$ and explained $57 \%$ of the variability of the NIHSS $24 \mathrm{~h}$ post-treatment (Nagelkerke determination coefficient, $R^{2}$ $=0.57)$. In this model core volume and the TTR individually accounted for 17 and $3.5 \%$ of the outcome variability respectively when NIHSS on admission and age were included in the null model as nuisance parameters (20).

\section{Linear Regression Model}

Figure 2 illustrates the amendable variables associated to a favorable stroke outcome. A logistic regression was performed to weigh the effects of the core volume and TTR on the likelihood that participants have a favorable stroke outcome $(\mathrm{mRS} \leq 3)$ at 90 days.

Table 3 shows the respective odd ratios and associated pvalues for the variables assessed in the prediction model. This logistic regression model was statistically significant to predict favorable outcomes $\left(R^{2}=0.57, \chi^{2}(61)=32.97, p<0.001\right)$ with a model AUC of 0.9 (sensibility: $90 \%$, specificity: $62 \%$ ).

This model explained $57 \%$ of the variability of the favorable stroke outcome (Nagelkerke determination coefficient, $R^{2}=$ $0.571)$ with $14 \%\left(R^{2}=0.142\right)$ of the variability explained by the core volume and $0.6 \%$ explained by the TTR $\left(R^{2}=0.006\right)$ when NIHSS on admission and age were included in the null model as nuisance parameters (20).

\section{DISCUSSION}

The main findings from this study are 2 fold. First, the ischemic core volume is more effective than TTR to predict both early and late favorable outcomes following successful LVO recanalization within $6 \mathrm{~h}$ of symptoms onset. Second, $40 \%$ of the variability of favorable outcomes fail to be apprehended by canonical predictors.

The findings of this study, albeit limited by its monocentric nature, are likely to be generalizable to other populations of LVO treated by thrombectomy within $6 \mathrm{~h}$ of symptoms onset. Indeed, the cohort matches closely to the characteristics of the pooled populations in the meta-analysis that included the five main trials that validated mechanical thrombectomy (MR CLEAN, ESCAPE, REVASCAT, SWIFT PRIME, and EXTEND IA) in terms of age, admission NIHSS, rate of ICA and M1 occlusion (21). Likewise, patients in our cohort achieved recanalization faster but within a 

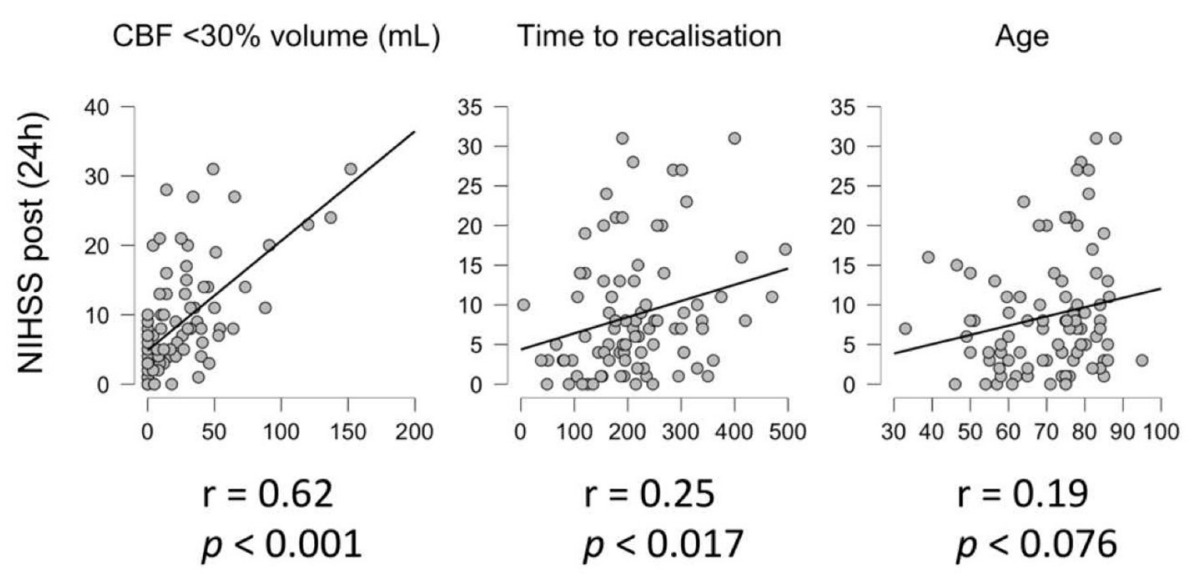

FIGURE 1 | Correlation analysis. Correlation between NIHSS 24 h post treatment and core volume (CBF < 30\%, left), time to recanalization (center) and age (right).

TABLE 2 | Linear regression coefficients for the variables assessed in the prediction model.

\begin{tabular}{lccc}
\hline & Coefficient & $\mathbf{9 5 \%} \mathbf{~ C l}$ & $\boldsymbol{p}$-value \\
\hline Age & 0.13 & -0.120 .178 & 0.086 \\
Admission NIHSS & 0.36 & 0.210 .57 & $<0.001$ \\
Time to recanalization & 0.19 & 0.040 .28 & 0.012 \\
CBF $<30 \%$ & 0.46 & 0.080 .16 & $<0.001$ \\
\hline
\end{tabular}

Cl, confidence interval; NIHSS, National Institutes of Health Stroke Scale; CBF, Cerebral Blood Flow.

similar timeframe ( 216 vs. $285 \mathrm{~min}$ ) than in the validation studies, and displayed a similar rate of favorable outcome ( $\mathrm{mRS} \geq 3: 67 \mathrm{vs.}$ 64\%) (21).

Over the past years, many predictions models have been proposed to isolate factors associated with favorable stroke outcomes (22). The generalizability of such models is always controversial as no single model is likely to address all situations, subgroups and local contexts. However, a common finding prior to the rise of endovascular thrombectomy (EVT), regardless of anterior LVO, was that simple clinical variables (e.g., the Six Simple Variables including age, pre-stroke functional status, living alone pre-stroke, being able to walk unaided, lift both arms off the bed and have a normal verbal Glasgow Coma Scale score) were found to be efficient in predicting independent survival after stroke (16, 23-25). The addition of imaging data like CT or diffusion-weighted magnetic resonance imaging (MRI) stroke volume (26) to clinical data does not seem to improve prediction accuracy (27).

In EVT, the Stroke Prognostication Using Age and NIHSS (SPAN) index developed for fibrinolysis therapy (17), displayed a similarly fair prognostic discrimination (18) that was improved by adding the weighted relative contribution of age and NIHSS at admission (multiplied by three) (28). Our study also highlights age and NIHSS at admission as main predictors of favorable outcome. However, those two canonical parameters only account for $40 \%$ of the variability found in favorable outcomes measured at $24 \mathrm{~h}$ and 90 days. Furthermore, TTR is a significant predictor for an early favorable outcome with only a marginal contribution to the prediction model accuracy, whereas it is not significant for a late favorable outcome. Thus, TTR is not a main contributor to LVO outcome within $6 \mathrm{~h}$ of symptoms onset.

Brain perfusion assessment in LVO $<6 \mathrm{~h}$ of symptom onset could, therefore, be relevant if we want to single out patients that will really benefit from EVT. Indeed, in LVO $<6 \mathrm{~h}$ of symptom onset, there is no significant mismatch to be found between the ischemic core and the penumbra in between 38 and $64 \%$ of cases, which sheds some doubt about the benefit/risk ratio and the cost-effectiveness of EVT in those patients $(29,30)$. Such lack of a significant mismatch and a large ischemic core both independently predict poor outcomes in LVO treated by EVT $<6$ h of symptom onset $(29,30)$. In our study, we focused on patients who benefited from successful recanalization therapy $<6 \mathrm{~h}$ of symptom onset to get a more accurate vision of the predictive value and weight of the ischemic core on a favorable outcome. The association between core volume and a favorable outcome in our cohort was both significant and relevant: the ischemic core volume in itself explained almost $20 \%$ of favorable outcome variability that was not accounted for by age or NIHSS. This fact shows that CTP in LVO $<6 \mathrm{~h}$ onset is important to predict a favorable outcome, much more so than TTR. This association between favorable outcome and core volume is also supported by CT angiogram collaterals status assessment studies. Indeed, collateral status is tightly associated to ischemic core volume (31) and shows a similar association with functional outcome regardless of the time from symptoms onset (32).

Still, in our model, $40 \%$ of outcome variability remains to be explained by other parameters. A ghost effect overestimating the stroke ischemic core volume could explain part of the model imprecision. However, while a ghost effect is found regularly in LVO, the mean overestimation is around $10 \mathrm{ml}(10)$, which seems too small comparatively to the $140 \mathrm{ml}$ sylvian artery perfusion volume to be responsible for significant effects (1). Thus, the remaining unpredicted favorable outcome variability 


\section{Probability}

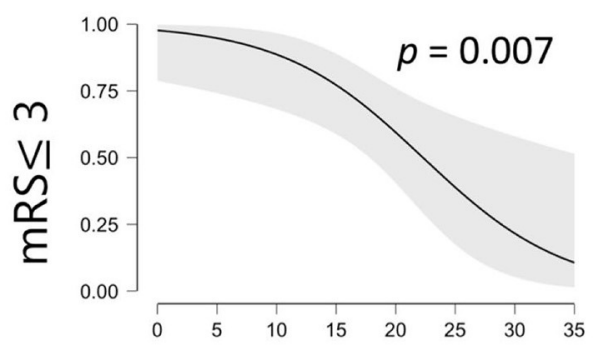

Admission NIHSS

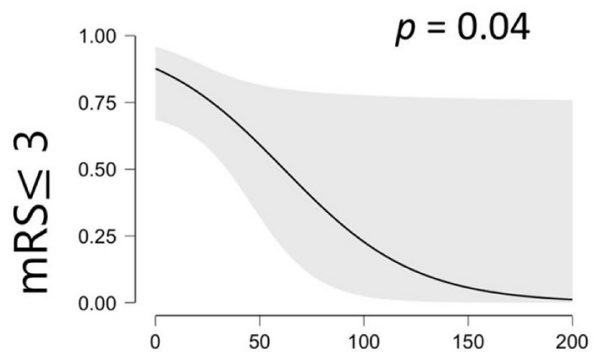

$\mathrm{CBF}<30 \%$ volume $(\mathrm{mL})$
Probability
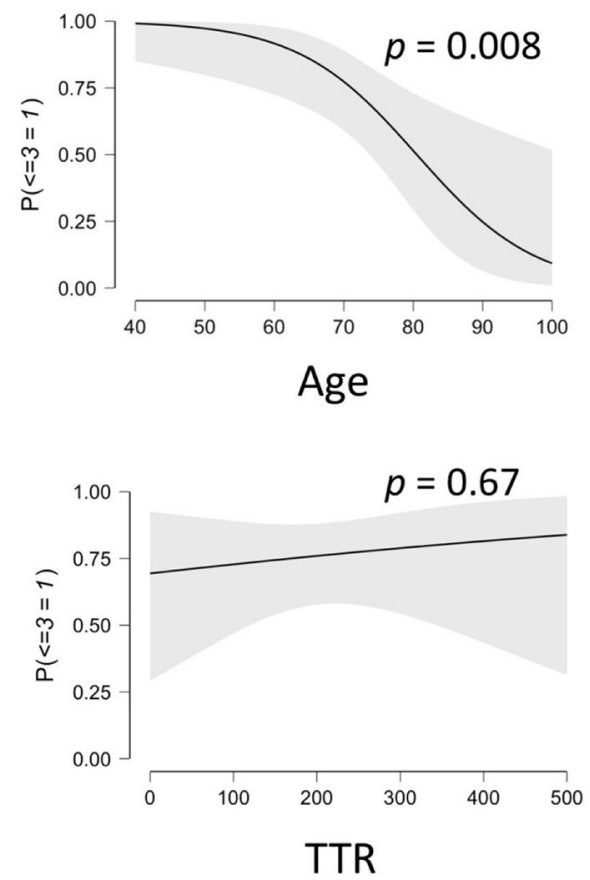

FIGURE 2 | |llustrates the probability of a favorable outcome ( $m R S \leq 3$ ) being associated to significant predictive variables. mRS, modified Rankin Scale; CBF, Cerebral Blood Flow; TTR, Time to Recanalization. The gray shaded area on each graph corresponds to the $95 \%$ confidence interval.

TABLE 3 | Odd Ratios of the variables assessed in the prediction model.

\begin{tabular}{lcc}
\hline & Odds ratio, [95\% Cl] & $\boldsymbol{p}$ \\
\hline Higher admission NIHSS & $0.85[-0.29-0.043]$ & 0.008 \\
Older age (years) & $0.99[-0.2-0.03]$ & 0.007 \\
Higher CBF <30\% volume & $0.97[-0.06-0.00]$ & 0.049 \\
TTR & $1.02[-0.060 .09]$ & 0.66 \\
\hline
\end{tabular}

Cl, confidence interval; NIHSS, National Institutes of Health Stroke Scale; CBF, Cerebral Blood Flow; TTR, Time to Recanalization.

must be found elsewhere. Predictive factors could come from intrinsic patient clinical variability or from the occurrence of complications. Indeed, the morbidity and mortality following a stroke are primarily related to cerebral complications in the first week, followed by medical issues from the second week onwards (e.g., infections, pressure sores, thrombo-embolic events), both of which play an increasing role in modeling the outcome (3338). While this hypothesis is worth further investigation, the fact that the model, as it is, explains the same amount of variability for early and late favorable outcome argue for a potential role of other acute cerebral compensatory mechanisms/failures that escape the conventional work-up. Indeed, several parameters not assessed by automated softwares like Rapid, such as venous outflow assessment from acute stroke angio-CT (39) or the quantitative lesion water uptake calculated from non-contrast head CT (40), have been shown to be associated with favorable outcomes. Similarly, treatment related parameters beyond TTR can provide prognostic information such as the luxury perfusion reflected by early venous filling after EVT that predicts early favorable outcome (13). These neuroimaging markers may provide an insight into the physiological effects following LVO that is both patient-specific and dynamic, and may thus complement other known clinical variables in predicting functional outcome.

\section{CONCLUSION}

Core stroke volume better explains outcome variability in comparison to the time to recanalization in anterior large vessel occlusion stroke with successful thrombectomy done within $6 \mathrm{~h}$ of symptoms onset. Still, a large part of outcome variability prediction fails to be explained by the usual predictors suggesting that further research for more accurate acute stroke outcome biomarkers is warranted to identify which patients would benefit the most from thrombectomy within $6 \mathrm{~h}$ of symptoms onset.

\section{DATA AVAILABILITY STATEMENT}

The raw data supporting the conclusions of this article will be made available by the authors, without undue reservation.

\section{ETHICS STATEMENT}

The studies involving human participants were reviewed and approved by Ethics Committee of Erasmus Hospital, Brussels, 
Belgium. Written informed consent for participation was not required for this study in accordance with the national legislation and the institutional requirements.

\section{AUTHOR CONTRIBUTIONS}

NL, SE, and GN: study design, data collection, analysis, and manuscript writing. $\mathrm{CD}, \mathrm{LJ}, \mathrm{NS}, \mathrm{BM}, \mathrm{TB}, \mathrm{AG}$, and $\mathrm{BL}$ : data

\section{REFERENCES}

1. van der Zwan A, Hillen B, Tulleken CA, Dujovny M. A quantitative investigation of the variability of the major cerebral arterial territories. Stroke. (1993) 24:1951-9. doi: 10.1161/01.STR.24.12.1951

2. Malhotra K, Gornbein J, Saver JL. Ischemic strokes due to large-vessel occlusions contribute disproportionately to stroke-related dependence and death: a review. Front Neurol. (2017) 8:651. doi: 10.3389/fneur.2017. 00651

3. Vagal A, Wintermark M, Nael K, Bivard A, Parsons M, Grossman AW, et al. Automated CT perfusion imaging for acute ischemic stroke: pearls and pitfalls for real-world use. Neurology. (2019) 93:888-98. doi: 10.1212/WNL.0000000000008481

4. Requena M, Olivé-Gadea M, Muchada M, Hernández D, Rubiera M, Boned S, et al. Direct to angiography suite without stopping for computed tomography imaging for patients with acute stroke: a randomized clinical trial. JAMA Neurol. (2021) 78:1099-107. doi: 10.1001/jamaneurol.2021.2385

5. Nogueira RG, Jadhav AP, Haussen DC, Bonafe A, Budzik RF, Bhuva P, et al. Thrombectomy 6 to 24 hours after stroke with a mismatch between deficit and infarct. N Engl J Med. (2017) 378:11-21. doi: 10.1056/NEJMoa1706442

6. Albers GW, Marks MP, Kemp S, Christensen S, Tsai JP, Ortega-Gutierrez S, et al. Thrombectomy for stroke at 6 to 16 hours with selection by perfusion imaging. N Engl J Med. (2018) 378:708-18. doi: 10.1056/NEJMoa1713973

7. Galimanis A, Jung S, Mono M-L, Fischer U, Findling O, Weck A, et al. Endovascular therapy of 623 patients with anterior circulation. Stroke. (2012) 43:1052-7. doi: 10.1161/STROKEAHA.111.639112

8. Agarwal S, Bivard A, Warburton E, Parsons M, Levi C. Collateral response modulates the time-penumbra relationship in proximal arterial occlusions. Neurology. (2018) 90:e316-22. doi: 10.1212/WNL.0000000000004858

9. Campbell BCV, Majoie CBLM, Albers GW, Menon BK, Yassi N, Sharma G, et al. Penumbral imaging and functional outcome in patients with anterior circulation ischaemic stroke treated with endovascular thrombectomy versus medical therapy: a meta-analysis of individual patient-level data. Lancet Neurol. (2019) 18:46-55. doi: 10.1016/S1474-4422(18)3031

10. Boned S, Padroni M, Rubiera M, Tomasello A, Coscojuela P, Romero $\mathrm{N}$, et al. Admission CT perfusion may overestimate initial infarct core: the ghost infarct core concept. J Neurointerv Surg. (2017) 9:669. doi: 10.1136/neurintsurg-2016-012494

11. Rotem S-H, Mor S, Chen B, Firas S, Elliot S, Ayelet E, et al. Infarct core reliability by CT perfusion is a time-dependent phenomenon. J Neuroimaging. (2020) 30:240-5. doi: 10.1111/jon.12692

12. Bulwa Z, Dasenbrock H, Osteraas N, Cherian L, Crowley RW, Chen M. Incidence of unreliable automated computed tomography perfusion maps. J Stroke Cerebrovasc Dis. (2019) 28:104471. doi: 10.1016/j.jstrokecerebrovasdis.2019.104471

13. Elands S, Casimir $\mathrm{P}$, Bonnet $\mathrm{T}$, Mine $\mathrm{B}$, Lubicz $\mathrm{B}$, Sjøgård $\mathrm{M}$, et al. Early venous filling following thrombectomy: association with hemorrhagic transformation and functional outcome. Front Neurol. (2021) 12:649079. doi: 10.3389/fneur.2021.649079

14. Jodaitis L, Ligot N, Chapusette R, Bonnet T, Gaspard N, Naeije G. The hyperdense middle cerebral artery sign in drip-and-ship models of acute stroke management. Cerebrovasc Dis Extra. (2020) 10:3643. doi: 10.1159/000506971

15. Austein F, Riedel C, Kerby T, Meyne J, Binder A, Lindner $\mathrm{T}$, et al. Comparison of perfusion CT software to predict collection and drafted manuscript for intellectual content. All authors contributed to the article and approved the submitted version.

\section{FUNDING}

GN is a Postdoctorate Clinical Master Specialists at the FRSFNRS (Brussels, Belgium). the final infarct volume after thrombectomy. Stroke. (2016) 47:2311-7. doi: 10.1161/STROKEAHA.116.013147

16. Knoflach M, Matosevic B, Rücker M, Furtner M, Mair A, Wille G, et al. Functional recovery after ischemic stroke-a matter of age: data from the austrian stroke unit registry. Neurology. (2012) 78:27985. doi: 10.1212/WNL.0b013e31824367ab

17. Saposnik G, Guzik AK, Reeves M, Ovbiagele B, Johnston SC. Stroke prognostication using age and NIH stroke scale: SPAN-100. Neurology. (2013) 80:21-8. doi: 10.1212/WNL.0b013e31827b1ace

18. Almekhlafi MA, Davalos A, Bonafe A, Chapot R, Gralla J, Pereira VM, et al. Impact of age and baseline NIHSS scores on clinical outcomes in the mechanical thrombectomy using solitaire FR in acute ischemic stroke study. AJNR Am J Neuroradiol. (2014) 35:1337-40. doi: 10.3174/ajnr.A3855

19. Saver JL, Goyal M, van der Lugt A, Menon BK, Majoie CBLM, Dippel DW, et al. Time to treatment with endovascular thrombectomy and outcomes from ischemic stroke: a meta-analysis. JAMA. (2016) 316:1279. doi: 10.1001/jama.2016.13647

20. Nagelkerke NJD. A note on a general definition of the coefficient of determination. Biometrika. (1991) 78:691-2. doi: 10.1093/biomet/78.3.691

21. Goyal M, Menon BK, van Zwam WH, Dippel DWJ, Mitchell PJ, Demchuk AM, et al. Endovascular thrombectomy after large-vessel ischaemic stroke: a meta-analysis of individual patient data from five randomised trials. Lancet. (2016) 387:1723-31. doi: 10.1016/S0140-6736(16)00163-X

22. Fahey M, Crayton E, Wolfe C, Douiri A. Clinical prediction models for mortality and functional outcome following ischemic stroke: a systematic review and meta-analysis. PLoS ONE. (2018) 13:e0185402. doi: 10.1371/journal.pone. 0185402

23. Counsell C, Dennis M, McDowall M. Predicting functional outcome in acute stroke: comparison of a simple six variable model with other predictive systems and informal clinical prediction. J Neurol Neurosurg Psychiatry. (2004) 75:401-5. doi: 10.1136/jnnp.2003.018085

24. Ayis SA, Coker B, Rudd AG, Dennis MS, Wolfe CDA. Predicting independent survival after stroke: a European study for the development and validation of standardised stroke scales and prediction models of outcome. $J$ Neurol Neurosurg Psychiatry. (2013) 84:288-96. doi: 10.1136/jnnp-2012-303657

25. König IR, Ziegler A, Bluhmki E, Hacke W, Bath PMW, Sacco RL, et al. Predicting long-term outcome after acute ischemic stroke: a simple index works in patients from controlled clinical trials. Stroke. (2008) 39:18216. doi: 10.1161/STROKEAHA.107.505867

26. Baird AE, Dambrosia J, Janket S, Eichbaum Q, Chaves C, Silver B, et al. A three-item scale for the early prediction of stroke recovery. Lancet. (2001) 357:2095-9. doi: 10.1016/S0140-6736(00)05183-7

27. Reid JM, Gubitz GJ, Dai D, Kydd D, Eskes G, Reidy Y, et al. Predicting functional outcome after stroke by modelling baseline clinical and CT variables. Age Ageing. (2010) 39:360-6. doi: 10.1093/ageing/afq027

28. Ospel JM, Brown S, Kappelhof M, van Zwam W, Jovin T, Roy D, et al. Comparing the prognostic impact of age and baseline national institutes of health stroke scale in acute stroke due to large vessel occlusion. Stroke. (2021) 52:2839-45. doi: 10.1161/STROKEAHA.120.032364

29. Seners P, Oppenheim C, Turc G, Albucher J-F, Guenego A, Raposo N, et al. Perfusion imaging and clinical outcome in acute ischemic stroke with large core. Ann Neurol. (2021) 90:417-27. doi: 10.1002/ana.26152

30. Olivot J-M, Albucher J-F, Guenego A, Thalamas C, Mlynash M, Rousseau V et al. Mismatch profile influences outcome after mechanical thrombectomy. Stroke. (2021) 52:232-40. doi: 10.1161/STROKEAHA.120.031929 
31. Vagal A, Menon BK, Foster LD, Livorine A, Yeatts SD, Qazi E, et al. Association between CT angiogram collaterals and CT perfusion in the interventional management of stroke III trial. Stroke. (2016) 47:5358. doi: 10.1161/STROKEAHA.115.011461

32. Vagal A, Aviv R, Sucharew H, Reddy M, Hou Q, Michel P, et al. Collateral clock is more important than time clock for tissue fate. Stroke. (2018) 49:21027. doi: 10.1161/STROKEAHA.118.021484

33. Weimar C, Roth MP, Zillessen G, Glahn J, Wimmer MLJ, Busse O, et al. Complications following acute ischemic stroke. Eur Neurol. (2002) 48:13340. doi: $10.1159 / 000065512$

34. Fuentes B, Castillo J, San José B, Leira R, Serena J, Vivancos J, et al. The prognostic value of capillary glucose levels in acute stroke: the glycemia in acute stroke (GLIAS) study. Stroke. (2009) 40:5628. doi: 10.1161/STROKEAHA.108.519926

35. Hotter B, Hoffmann S, Ulm L, Montaner J, Bustamante A, Meisel C, et al. Inflammatory and stress markers predicting pneumonia, outcome, and etiology in patients with stroke: biomarkers for predicting pneumonia, functional outcome, and death after stroke. Neurol Neuroimmunol neuroinflammation. (2020) 7:e692. doi: 10.1212/NXI.00000000000 00692

36. Leonardi-Bee J, Bath PMW, Phillips SJ, Sandercock PAG. Blood pressure and clinical outcomes in the international stroke trial. Stroke. (2002) 33:131520. doi: 10.1161/01.STR.0000014509.11540.66

37. Yong M, Kaste M. Association of characteristics of blood pressure profiles and stroke outcomes in the ECASS-II trial. Stroke. (2008) 39:36672. doi: 10.1161/STROKEAHA.107.492330

38. Viitanen M, Winblad B, Asplund K. Autopsy-verified causes of death after stroke. Acta Med Scand. (1987) 222:4018. doi: 10.1111/j.0954-6820.1987.tb10956.x
39. Faizy TD, Kabiri R, Christensen S, Mlynash M, Kuraitis G, Mader MM-D, et al. Association of venous outflow profiles and successful vessel reperfusion after thrombectomy. Neurology. (2021) 96:e2903-11. doi: 10.1212/WNL.0000000000012106

40. Broocks G, Kemmling A, Teßarek S, McDonough R, Meyer L, Faizy TD, et al. Quantitative lesion water uptake as stroke imaging biomarker: a tool for treatment selection in the extended time window? Stroke. (2021) 53:201-9. doi: 10.1161/STROKEAHA.120.033025

Conflict of Interest: The authors declare that the research was conducted in the absence of any commercial or financial relationships that could be construed as a potential conflict of interest.

Publisher's Note: All claims expressed in this article are solely those of the authors and do not necessarily represent those of their affiliated organizations, or those of the publisher, the editors and the reviewers. Any product that may be evaluated in this article, or claim that may be made by its manufacturer, is not guaranteed or endorsed by the publisher.

Copyright (C) 2022 Ligot, Elands, Damien, Jodaitis, Sadeghi Meibodi, Mine, Bonnet, Guenego, Lubicz and Naeije. This is an open-access article distributed under the terms of the Creative Commons Attribution License (CC BY). The use, distribution or reproduction in other forums is permitted, provided the original author(s) and the copyright owner(s) are credited and that the original publication in this journal is cited, in accordance with accepted academic practice. No use, distribution or reproduction is permitted which does not comply with these terms. 